\section{UKCPR}

University of Kentucky

Center for

\section{Discussion Paper Series}

DP 2009-02

Poverty Research

ISSN: 1936-9379

\title{
The organization of discipline: From performance management to perversity and punishment
}

\author{
Joe Soss \\ University of Minnesota \\ Hubert H. Humphrey Institute of Public Affairs \\ Richard Fording \\ University of Kentucky \\ Department of Political Science \\ Sanford F. Schram \\ Bryn Mawr College \\ Graduate School of Social work and Social Research
}

January 2009

Preferred citation

Soss, J., Fording, R., and Schram, J. (2009, January). The organization of discipline: From performance management to perversity and punishment. University of Kentucky Center for Poverty Research Discussion Paper Series, DP2009-02. Retrieved [Date] from http://www.ukcpr.org/Publications/DP2009-02.pdf.

Author correspondence: Richard Fording, University of Kentucky, Center for Poverty Research, 302A Mathews Building, Lexington, KY 40506-0047. E-mail: rford@uky.edu.

University of Kentucky Center for Poverty Research, 302D Mathews Building, Lexington, KY, 40506-0047 Phone: 859-257-7641; Fax: 859-257-6959; E-mail: jspra2@uky.edu 
This research has been supported by the Annie E. Casey Foundation, the University of Kentucky Center for Poverty Research, the Institute for Research on Poverty at the University of Wisconsin, and the Center on Ethnicities, Communities and Social Policy at Bryn Mawr College. We thank Adam Butz and Sarah Martyn Crowell for research assistance, and we are grateful to representatives of the Florida Department of Children and Families and Workforce Florida, Inc. for the data used in this paper. 
Over the past few decades, poverty governance in the United States has been transformed by the convergence of two powerful reform movements. The first, often referred to as "paternalist," has shifted poverty governance from an emphasis on rights and opportunities to a stance that is more directive and supervisory in promoting preferred behaviors among the poor. The second, often described as "neoliberal," has shifted governance away from federal government control toward a system that emphasizes policy devolution, privatization, and performance competition. During this period, public officials have proved remarkably willing to hand policy control over to lower jurisdictions and private providers. They have been equally eager to use public policies in ways that overtly promote values, enforce obligations, and curtail deviance among the poor. In the era of neoliberal paternalism, poverty governance has become more dispersed in its organization, more muscular in its normative enforcement, and more firmly rooted in the logics of performance-based accountability and market competition.

At the frontlines of welfare provision, the resulting system blends autonomy and discipline in complex ways. Under the Temporary Assistance for Needy Families (TANF) program, welfare-to-work programs have been reorganized to reflect the principles of "the new public management" - a reform movement that has sought "to replace traditional rule-based, authority-driven processes with marketbased, competition-driven tactics” (Kettl 2005: 3). Since 1996, state TANF programs have moved decisively toward decentralized systems designed to facilitate locally-tailored solutions and innovations (Gainsborough 2003). At the same time, states have contracted with independent non-profit and for-profit organizations and used competitive procedures to stimulate innovation (Heinrich 2000; Dias and Maynard-Moody 2006). At the frontlines, case managers have been given greater authority to assess clients’ needs and allocate benefits, services, and penalties (Hasenfeld et al. 2004; Brodkin 1997).

The counterpart to all this autonomy, however, is a more vigorous system of discipline. At the heart of this system lies the practice known as performance management. "The beginning of the twentyfirst century,” Donald Moynihan (2008: 3) writes, “finds us in an era of governance by performance management,” and nowhere is this more the case than in welfare programs for the poor. By establishing 
outcome benchmarks focused on work participation and placement, federal and state officials define the goals of service provision and the terms of its evaluation. Choice sets for local actors consist primarily of alternative means toward mandated ends. With these benchmarks in place, sophisticated information systems are used to monitor frontline activities and measure priority outcomes. And based on the outcomes of performance competition, financial rewards and penalties are distributed to incent preferred behaviors and bring lagging service providers to heel. In welfare-to-work programs, performance systems now serve as the core technology for monitoring contract compliance; they guide decisions about when to renew or terminate contracts with local providers; they provide state officials with a yardstick and a prod for the achievement of program goals; and they constitute the major way in which state TANF programs are evaluated by federal officials (Ridzi 2004; Ewalt and Jennings 2004).

Proponents rarely conceptualize performance management as a system of discipline. In celebratory rhetoric, it is presented as a way to harness the dynamic energies of markets, improve the evidentiary basis for policy choices, and reconcile policy experimentation with public accountability (Talbot 2005). The implicit promise is that local actors will be "freed" to go their own ways and then, later, will be judged by their performance and given the information they need to improve. The reality, however, entails a more complex interplay of structure and agency (Moynihan 2008; Radin 2006). The focusing effects of outcome benchmarks, the pressures of competition, the prospects of incurring a reward or penalty, the awareness that one is being closely monitored: these features of performance management do more than just make agents accountable; they reshape agency itself. Indeed, performance management is disciplinary, not just in the sense that it involves the allocation of penalties, but also in the deeper sense suggested by Michel Foucault (1997): the use of organized techniques to produce self-regulating subjects (i.e., service providers) who, under conditions of apparent autonomy, conduct themselves in ways that are consonant with prevailing institutions, values, and interests.

On the other side of the case manager's desk, clients experience their own mix of autonomy and discipline. In the neoliberal era, clients have been recast as free market actors: they are "customers” who freely enter into contracts to perform specified behaviors in exchange for cash and in-kind benefits. The 
essence of paternalist welfare reform, however, is an ethos of transformative discipline. The "freedom" given to clients is the freedom to succeed or fail in performing mandated behaviors. Their activities are closely monitored, and they are subjected to penalties for noncompliance. Paternalism directs human service organizations to pursue a kind of "transformative moral work" designed to reform aid recipients and move them into mainstream institutions (Hasenfeld et al. 2002). By directing, assisting, monitoring, and penalizing client behaviors, paternalism aims to create self-regulating subjects who will follow preferred behavioral scripts after they exit the TANF program (Mead 1998, 2000, 2005).

The paternalist tool of discipline par excellence is the sanction - a penalty that reduces or eliminates aid when a welfare client fails to comply with behavioral requirements. In a system that conditions public aid on client behavior, sanctions are the policy tools that put muscle behind a host of participation requirements. Sanctions have been key forces driving the major outcomes of welfare reform since 1996 and, today, remain central to the daily activities of welfare case managers (Pavetti et al. 2004). Researchers using econometric methods have analyzed sanctioning extensively, producing an impressive empirical portrait of how client characteristics relate to penalty patterns (Fording, Soss and Schram 2007; Wu et al. 2006; Pavetti, Derr and Hesketh 2003; Hasenfeld et al. 2004; Kalil et al. 2002). To date, however, such studies have paid virtually no attention to how sanctioning may be influenced by performance management or other aspects of organizational structure, process, and culture.

The omission is striking because it ignores the obvious fact that sanction decisions are made in the context of organizational routines, by actors who occupy specific organizational positions. Leading studies of welfare implementation reproduce this blind spot in reverse, illuminating important managerial and organizational dynamics while saying little about disciplinary logics and practices (Riccucci 2005; Lurie 2006). As a result, scholars have failed to address one of the most distinctive and critical features of contemporary poverty governance: the interplay of paternalist systems for disciplining clients (e.g., sanctions) and neoliberal systems for disciplining service-providers (e.g., performance management).

In what follows, we seek to bridge this divide. Drawing on intensive field research and administrative data from the Florida Welfare Transition (WT) program, we present an empirically- 
grounded analysis of how organizations carry out the work of discipline in a decentralized, performancedriven policy system. A central theme of our analysis is that, as Foucault (1980) suggests, disciplinary power shapes consciousness and behavior in deep ways yet is always incomplete - always the occasion of subversion and resistance. In this vein, we begin by showing how performance management contains internal contradictions that, on the one hand, succeed in shaping behavior at the frontlines of welfare reform but, on the other, produce perverse organizational responses that subvert the underlying goals of policymakers. We then turn to the relationship between performance systems and sanctioning. Using administrative data, we establish a clear pattern linking the disciplinary pressures of performance management to disciplinary sanctions directed at clients. To explain this relationship and clarify its underlying mechanisms, we draw on our field research at the frontlines of the WT program. Our analysis underscores that sanctions are more than just responses to individual misbehavior. Because sanctioning practices must be organized, sanctioning patterns are partly organizational products. To explain them, we must understand how the work of welfare provision is organized and managed, why it operates as it does, and how the structuring of organizational routines and priorities shapes disciplinary action.

\section{Case Selection: Why Study the Florida WT Program?}

Our study focuses on the Florida WT program, not because it is typical of all state TANF programs, but because it provides an ideal opportunity to analyze disciplinary action in a decentralized system of poverty governance. First, as a leading practitioner of "second-order devolution" (Gainsborough 2003), Florida has constructed one of the most decentralized TANF programs in the country. Frontline services have been contracted out to non-profit and for-profit providers throughout the state, and primary authority over the WT program has shifted down to 24 local public/private "Regional Workforce Boards” (RWBs). RWBs are responsible for planning, policy development, contracting, and oversight of local one-stop delivery systems. Several regions encompass more than one county, and RWBs often set policy in ways that allow county offices to have some discretion. The regional boards are overseen, not by state agencies, but by a statewide public/private partnership called Workforce Florida, Inc. (WFI). The Florida Department of Children and Families (DCF), a conventional state agency, 
receives the federal TANF block grant and maintains responsibility for eligibility determination. But otherwise, Florida stands out among American states for its emphasis on local control and privatization within a work-oriented TANF program (Botsko et al. 2001: 7).

Second, Florida scores high on factors that raise the importance of sanction processes. After 1996, Florida adopted "some of the strictest time limits and work requirements in the nation" and broadened the pool of clients subject to sanctions by creating "few possibilities for exemptions" (Botsko et al. 2001: 4). The sanctions themselves also fall at the strong end of the continuum, resulting in an immediate, full-family loss of TANF benefits and a reduction of Food Stamp benefits to the fullest extent permitted by federal law (Botsko et al. 2001: 6). Moreover, Florida WT providers employ these sanctions at an extremely high rate compared to other states with full-family sanctions. ${ }^{1}$ According to Florida DCF, sanctions were the most common cause of TANF case closings in fiscal year 2003, accounting for 31 percent of closings vs. 21 percent for increased earnings. And not surprisingly, given the program's focus on work discipline, the most common reason for sanctioning was noncompliance with a requirement related to participation in countable work-related activities (AWI 2004).

Third, to monitor and guide local disciplinary practices, Florida has developed an extensive system of performance management. Under this system, each region is expected to meet a set of performance standards for outcomes measured by the statewide board. The board negotiates with each RWB to establish a region-specific set of performance goals. Performance relative to these goals is then measured and used as a basis for state-level evaluations of regions and RWB evaluations of contracted service providers. Contract payments are tied directly to the achievement of performance goals, and local contracts often specify additional goals related to statewide performance measures.

\footnotetext{
${ }^{1}$ Applying the panel method advocated by Pavetti, Derr and Hesketh (2003) to Florida administrative data, we find that 47 percent of the adults who entered TANF in November 2001were sanctioned at least once in the next 18 months. Using a similar method, Pavetti, et al. (2004) report that Illinois and New Jersey had full-family sanctioning rates of 13 and 17 percent, respectively, during this same time period. Pavetti, et al. (2004) also report a full-family sanctioning rate for South Carolina, but only across a period of ten months. The South Carolina sanctioning rate for this period was 5 percent, while the comparable sanctioning rate in Florida was 43 percent.
} 
Performance in the WT program is closely tracked on a monthly basis, and results are disseminated to providers and the public via the AWI website. The centerpiece of this system is "the red and green report,” so called because it ranks the 24 regions based on performance scores, coloring them red if they are in the bottom quartile, green if they are in the top quartile, and white if they are in between. During the period of our study, the red and green reports included three items bearing specifically on the WT program. The first was the WT "entered employment rate," based on the percent of all case closures that closed for reasons due to taking paid employment. The second was the WT "employment wage rate" based on the average initial wage earned by clients who left welfare for work (expressed as a percentage of the regionally adjusted Lower Living Standard Income Level for a family of three). The third was the "welfare return rate," based on the rate at which clients from closed cases (due to employment) returned to the WT program.

Performance on the red and green report is taken very seriously at all levels of the WT program. It is not hard to see why. Green scores can qualify a region for additional funding to undertake program improvements and allow a region to enter competitions for additional resources allocated by WFI. For service providers, red scores can mean the difference between contract renewal and termination. Between these extremes, service providers typically lose "pay points” as a result of weak performance rankings, and regions are likely to get unwanted scrutiny from the state board if their performance rankings fall.

In short, actors at all levels of the Florida system expect their success or failure in meeting performance goals to be closely monitored, widely publicized, and consequential. As a result, the Florida WT program offers a superb opportunity to examine the convergence of strong forms of sanctioning, decentralization, and performance management. The program is not representative in the microcosmic sense of a statistical sample; it is representative in the analytic sense that it offers an unambiguous crystallization of policy developments that have occurred in varying shades of grey throughout the United States. In Florida, we see each development in strong form, and we see them in conjunction. 


\section{Performance Pressures and Organizational Behavior: Perversity in the Field}

How do local organizations respond to performance pressures in the Florida WT program? In principle, the new public management suggests they should do so by pursuing innovations that advance statewide goals and improve the programs available clients. The logic of this model is fairly straightforward. Devolution should free local actors to innovate in response to local needs and to experiment with diverse service-delivery approaches. Statewide performance feedback should provide local actors with the information they need, not only to learn from their own mistakes and achievements, but also to identify successes in other regions and emulate their best practices. Competitive performance pressures should provide local actors with strong incentives to make use of this information, learn from other regions, and adopt program improvements that work.

Leading studies suggest many reasons why, in practice, service-providing organizations may deviate from this script. Performance indicators present local organizations with ambiguous pieces of information that get "selected, interpreted, and used by actors in different ways consistent with their institutional interests” (Moynihan 2008: 9). Performance pressures often fail to stimulate positive innovations because managers lack authority to create change, learning forums and processes are weak, and organizational routines and cultures prove persistent (Moynihan 2006, 2008). Moreover, the "tunnel vision” created by performance numbers can lead local actors to innovate in perverse ways that subvert important programmatic goals. Performance pressures may divert attention from important-butunmeasured values and activities (Radin 2006) and, in an effort to boost their numbers, organizations may engage in “creaming” practices that direct "services to those already close to being 'job-ready' at the expense of those with barriers to employment” (Considine 2003: 71; Bell and Orr 2002; Heckman, Heinrich and Smith 2002; Sprigings 2002).

Drawing on almost three years of intensive field research in the Florida WT program, ${ }^{2}$ this section extends existing critiques of performance management by explaining (a) how strong performance

\footnotetext{
${ }^{2}$ Our field data cover the period from March 2005 to January 2008. During this period, we conducted in-depth interviews with state-level officials, regional board members, program supervisors, and case managers. We observed
} 
pressures undercut the very kinds of learning and innovation they are designed to promote and (b) why local organizations cope with performance pressures by innovating in perverse ways. Our findings echo some themes from previous research, but we also go beyond these studies by pointing to core contradictions that subvert and undermine the rationality project of the new public management.

In the field, our research confirms that performance concerns are deeply rooted in the consciousnesses of local WT personnel. Regional officials and program managers expect to be held accountable for the outcomes they produce; they carefully scrutinize performance reports and keep a close eye on other regions; and they express a strong desire to improve performance through evidence-based revisions of practice. Local officials routinely describe themselves as following a "business model” in which welfare-to-work outcomes are the "products” and performance is exchanged for payments.

In this regard, state officials repeatedly emphasize the need for regions to "make their bogey" (i.e., meet performance goals). Regional officials match this level of concern and affirm that performance measures drive their decision making. As one local manager explained, "We're at the bottom of the chain, and we look up to [the state level to] see what's important. And the performance measures are how we know. When you tell me I need to do participation rate, I know what my priorities are. And that's where we spend our time.” Another local official summarized: “This whole process with the Welfare Transition program, it’s a number thing. It's about the numbers. Your participation rate, your employment rate...”

Interviews at all levels of the WT program confirm that performance anxieties motivate organizational behavior. Yet they also point to deep contradictions in the new public management that subvert the promises of organizational learning and program innovation. Consider first the double-edged nature of competition and its relation to trust. In theory, performance competition is supposed to encourage regional managers to learn from one another's experiments. Yet this same system also encourages managers to view other regions as competitors who have a stake in outperforming them. Our

sanction training workshops for frontline case managers, meetings of region-level staff, and intake and orientation sessions with new WT applicants. Our field research focused most intensively on four of Florida's 24 workforce regions, where we conducted more than sixty in-depth interviews with all relevant frontline workers. 
site visits make clear that the diffusion of innovations requires a modicum of trust, and this trust can be undermined by highly competitive performance systems.

Echoing others we spoke with, one local manager stated unequivocally that regions try to maintain a competitive edge by guarding their best innovations as "trade secrets" and, in this same interview, asked us not to tell other regions about new techniques being tried at her one-stop. Another stated that high-performing regions "are cheating as far as the day is long” and that, in addition to being unfair, this practice made policy learning impossible: “They can’t tell you their 'best practices’ because their practice is cheating. So if this is going to be a competitive game, we need to start playing by the same game.” As these statements suggest, competition works at cross-purposes with policy learning by encouraging local actors to distrust the performance numbers that other regions produce, the best practices that other regions recommend, and the wisdom of sharing their own positive innovations.

The "creative counting" that local officials cite as a basis for distrust is, indeed, a widespread practice that merits attention in its own right. Prior studies have noted, of course, that local managers may be tempted to fiddle a bit with the numbers as a way to improve their apparent performance (e.g., Radin 2006). What scholars have rarely highlighted, however, is how tensions within the new public management, between decentralized managerial control and centralized performance systems, tend to make such perversities more likely. Local organizations in a devolved system are supposed to exercise discretion in deciding how to respond to performance pressures. In principle, they are supposed to use local knowledge to select the most effective and efficient program strategy for their locale. But programmatic effectiveness and efficiency are not the only ways that organizational strategies differ. From an organizational perspective, some paths of innovation are easier to pursue than others.

In the WT program, serious reforms designed to deal more effectively with problems of poverty and work are (not surprisingly) often viewed as difficult to achieve, and their performance effects are usually seen as distant and uncertain. By comparison, it is far easier to change how one classifies existing activities and counts measured behaviors. As a result, as one local official told us forthrightly, "people game the numbers all the time.” Indeed, in describing efforts to meet the required participation rate, 
another regional official explained: "You have to do all sorts of things to fill the participation hours. We've got a client who we found out was taking her pastor to church on Sunday. We went out and asked her pastor to sign on saying this was community service. The trick is to find out what people are already doing and find a way to count it as work or community service. This is how you have to do it.”

Policy learning and program innovation also founder on a third dynamic in the WT program and, here again, the problem can be traced to tensions between devolution and performance management. In principle, these two elements of the new public management are supposed to work hand in hand to promote the diffusion of best practices. Yet there is a deep tension between the two. Performance reports and efforts to publicize best practices function as parts of a broader discourse suggesting that "what worked there can work here too.” By contrast, the discourse that justifies state-to-local devolution prizes locally-tailored solutions and trumpets the idea that localities have radically different needs, goals, populations, and capacities. Not surprisingly, these two ideas clash in the consciousness of the local manager. When presented with performance-boosting innovations from other regions, local officials cite a litany of characteristics that distinguish the region of origin from their own. Resource differences are also sometimes cited, as in the case of one official who stated flatly: "There are best practices that there is no way we can implement or staff.” The deeper tension, however, is between a discourse that denigrates “one size fits all” ideas and celebrates local uniqueness, on one side, and a system that treats localities as comparable and seeks to generalize innovations across them, on the other. One local official spoke for many when he deployed the discourse of local differences to challenge the wisdom of having regions compete on the basis of performance: "Philosophically, to me it makes more sense to compare us against us. Don’t compare us against Miami. Don’t compare us against Orlando. Compare us against us.”

A fourth dynamic also disrupts the link between performance measurement and positive innovation - a dynamic we have not seen noted and will call "stream-creaming." Previous studies of creaming have generally focused on a single program. Such studies suggest that when performance standards are high, organizations may cope by focusing their energies on the clients who are easiest to lift above a measurement threshold (Bell and Orr 2002; Considine 2003; Dias and Maynard-Moody 2006). In 
an era of service integration and multi-program one-stop centers, however, for-profit providers often hold contracts related to several program streams at once. Within each stream, profitability depends on meeting contract "pay points" that are tied to performance benchmarks. As one manager put it, "If we make it [the performance standard] we get paid; then if we don't, we get zero.”

Thus, the profitability of the operation as a whole can be increased by raising efforts across the board, by creaming clients in each program, or by strategically focusing on programs that offer "softer" pay-point targets. The latter is what we mean by stream-creaming. When state officials raise performance standards in a program, they hope that organizations will devote greater effort to the program and reach for higher levels of performance. But when providers are contracted for multiple program streams, they may have incentives to do the opposite - that is, to reduce their efforts in the program that now has tougher benchmarks and shift their energies to programs where pay points and profits seem easier to obtain. In discussing higher performance benchmarks recently put in place for the WT program, one local manager told us, "If they are going to make our profit closely tied to something that is so hard to fully obtain, there will be problems.” When asked to elaborate, he explained that the contracted provider would abandon efforts to meet an unrealistic goal and use its resources to meet pay points in another program. In addition, the company would seek new program streams with more profitable targets. "[My employer] is committed to this welfare industry but they need to make a profit as well. We have been trying to diversify our services and clientele. For instance, we are now working with ex-offenders and things like that. We provide the support system for ex-offenders who are coming out of jail.”

Fifth and finally, when local actors respond to performance pressures, they also confront "easy versus hard” strategies along an additional dimension: working to develop and serve the existing client pool or trying to select a client pool that will make it easier to meet performance goals. Evidence from all the regions we studied suggests that the latter path is usually seen as easier. Accordingly, creative efforts to innovate are often directed toward reshaping the clientele rather than serving them more effectively - a practice that may be seen as a separate variant of the traditional creaming concept. 
In this regard, it is instructive to consider the organizational innovations that occurred in what we will call "Region A" in 2005. Interviews in Region A yielded some competing details about the events, but the broad outlines of the story were consistent across interviewees. In the early months of 2005, representatives of Region A attended a meeting with other regional officials where they were publicly criticized for having low performance numbers. As a direct result of this meeting, regional officials decided to overhaul key features of the local operation. Acting on the assumption that low performance numbers were a result of having too many clients who were "not serious enough," Region A officials chose a path of action designed to trim the caseload down to a more motivated core of clients. The relevant changes went into effect around the time of June 2005 and included the following:

1. Intake and orientation procedures were revamped so that applicants would need to attend daily classes for at least one week before having their application for benefits submitted. Forty hours of class attendance was required, and applicants who missed a class or showed up inappropriately dressed were required to start over the following week.

2. Intake meetings with new applicants were redesigned to emphasize the significant time investments demanded by program requirements, the limited amount of assistance available for meeting these requirements, and the fact that these requirements could be avoided if applicants chose to pursue only Medicaid and Food Stamp benefits. As one case manager responsible for intake explained, "Doing the overview presentation, what I kinda tell them is that, if you're in a situation right now where... transportation is a hindrance for you, you may want to reconsider getting your cash assistance open because you're going to be required to participate in this program on a daily basis."

3. The region instituted a more frequent and intensive Quality Assurance system for monitoring caseworkers' handling of sanctions and work participation.

4. The region moved to a new system for "curing" sanctions. In the past, a sanctioned client could reenter the caseload and reinstate benefits simply by contacting her caseworker and beginning to document work hours again. Under the new system, only one local staff member was given authority to sign off on the return of a sanctioned client, and this staff member was made available to clients on only one day each week, for two hours. Sanctioned clients who missed this window would have to wait another week to return.

Staff from Region A consistently reported that these program innovations had major effects on the region's caseload and operations. Figure 1, based on an analysis of administrative data, corroborates this perception. Between January 2003 and June 2005, the caseload of Region A tracked closely with caseloads in other regions of the state. Both trends rise and fall in a seasonal pattern, with Region A showing slightly higher peaks and troughs than the state average. In the months immediately prior to June 
2005, the two trend lines lie right one top of each other. Immediately after this date, however, the caseload in Region A falls precipitously. Indeed, despite the fact that caseloads were falling across the state during this period, Region A's caseload falls so quickly that it produces a substantial gap in relation to the state average. Moreover, while Region A's caseload had previously been more responsive to seasonal ebbs and flows, it now becomes less responsive than caseloads in other regions of the state. From June 2005 to July 2006, Region A’s caseload fell by an astonishing 53 percent.

[Figure 1]

As a disciplinary regime, then, the performance ethos is powerful yet incomplete. It is powerful in the sense that it shapes the thinking of regional and local officials, focuses organizational behavior, and motivates efforts to innovate at the frontlines. It is incomplete, however, because organizations on the ground retain substantial discretion in the ways they use performance information and respond to performance pressures. In the WT program, performance is the name of the game for local service providers. But organizations typically adapt in perverse ways, and internal contradictions embedded in the new public management work systematically against policy learning and program improvement.

\section{Performance Pressure and Sanctioning: A Statistical Analysis of Administrative Data}

With this analysis in hand, we may turn to the question of how performance pressures affect the use of disciplinary sanctions at the frontlines of the WT program. As noted earlier, studies of sanctioning have largely ignored the organizational forces that structure and guide case managers' decisions to allocate penalties. As the preceding section makes clear, performance systems stand out as a key factor in this regard. Do local providers respond to performance pressures by sanctioning WT clients?

To test this conjecture, we take advantage of detailed administrative data provided by the Florida DCF. Because our field research suggests that performance pressures are pervasive in the WT program, we begin with what we term the Chronic Pressure hypothesis: sanction rates should be higher in a system of strong ongoing performance pressures. Chronic pressures, by definition, do not vary enough to permit a statistical analysis of short-term fluctuations within the current system. Thus, evidence for this hypothesis must be derived from comparative indicators. We can begin with a piece of prima facie 
evidence (suggestive at best) that has already been noted in our description of the Florida system: Florida has one of the strongest performance systems in the country, and it sanctions clients at a higher rate than any state studied by researchers to date. One way to strengthen this evidence is to conduct a longitudinal analysis of systems change within Florida itself. In July 2000, Florida shifted from the less performancefocused WAGES program to the more performance-driven WT program. ${ }^{3}$ Thus, the effects of chronic pressures should be revealed in a comparison of sanction rates before and after this development.

Figure 2 tracks the average sanction rate for Florida workforce regions from January 2000 to April 2004, based on a three-month moving average of the percentage of the adult caseload receiving a sanction. The trend line is clearly consistent with the Chronic Pressure hypothesis. The statewide sanction rate rises significantly after July 2000 (denoted by the vertical line in the figure) and, under the WT performance system, stays continually above its rate under the WAGES program. Indeed, the average statewide sanction rate from January to June 2000 was 9.02 percent. Between July 2000 and April 2004, the sanction rate was 11.47 percent, a percentage increase of roughly 27 percent.

[Figure 2]

Although chronic performance pressures are felt throughout the state, evidence for their effects can also be bolstered by comparing responses across different types of service-providing organizations. Since its inception, the WT program has been implemented by contracting the operation of local one-stop centers to a variety of nonprofit and for-profit organizations. In theory, the key difference between the two should be the "nondistribution constraint" - i.e., the inability of nonprofit organizations to distribute profits to managers and shareholders. Because of this constraint, some argue that nonprofit managers will be less concerned about cost minimization and, hence, more likely to "expend resources to serve segments of the public that would otherwise be seen as too costly or unprofitable to serve” (Heinrich 2000). Conversely, performance incentives and pay points may be emphasized for frontline workers to a greater degree in for-profit organizations (Gilman 2001). Following this logic, if performance systems

\footnotetext{
${ }^{3}$ With the onset of the WT program in July 2000, Florida implemented a new information system focused on tracking performance information, One-Stop System Tracking (OSST), as well as stronger procedures for monitoring, disseminating, and rewarding/penalizing performance.
} 
create chronic financial pressures that raise sanction rates, one would expect this effect to be greater in for-profit than non-profit organizations. Accordingly, our Organizations Hypothesis predicts that, all else equal, for-profit providers will sanction clients at a higher rate than nonprofit providers.

To test this hypothesis, we use a sample that consists of all adults who participated in TANF for at least one month during the period from November, 2003 through April, 2004. Our dichotomous dependent variable indicates if a client was sanctioned during this period (1) or not (0). Our dichotomous measure of organizational form equals 1 for the 16 regions where one-stop centers were operated by forprofit firms and 0 for the 8 regions that contracted with nonprofit organizations. We control for a number of variables suggested by the literature on sanctioning, including client characteristics and measures of local economic and political context (Fording, Soss and Schram 2007; Pavetti, Derr and Hesketh 2003).

The results presented in Table 1 indicate that, even after controlling for these conventional factors, WT clients were significantly more likely to be sanctioned if they participated in regions where one-stop centers were operated by for-profit firms. Indeed, the odds of receiving a sanction are estimated to be $25 \%$ higher for such clients, relative to similar clients served by nonprofit providers.

[Table 1]

Although the most significant feature of performance pressure in the WT program is its ubiquity for service providers, more precise tests are possible if we examine how local sanction patterns relate to episodic changes in performance feedback over time. The pervasiveness of performance anxieties in the WT program should produce a "ceiling effect" that makes it difficult to observe whether low performance rankings prompt short-term increases in sanctioning. Yet, as described earlier, regional officials say they pay close attention to performance reports and are eager to respond in ways that might improve their numbers. Accordingly, we pursue three episodic hypotheses. ${ }^{4}$

\footnotetext{
${ }^{4}$ Unfortunately, because we have been unable to obtain longitudinal data on local one-stop operators, we are unable to test an episodic variant of our organizations hypothesis - i.e., whether for-profits and nonprofits vary in the ways they respond to declining performance feedback over time.
} 
- The Feedback Hypothesis: Because regional officials and case managers experience increased performance pressure in the wake of negative performance feedback, we expect regional sanction rates to increase in response to declining regional performance.

- $\quad$ The Clientele Hypothesis: Because the WT system penalizes regions that are less successful in moving clients into the workforce, we expect negative performance feedback to raise sanction rates to a greater degree for clients who are "harder to serve" or viewed as lacking work motivation.

- The Ideology Hypothesis: Because providers in politically conservative locales tend to rely more heavily on sanctions to motivate clients (Fording, Soss, and Schram 2007), we expect negative performance feedback to stimulate sanctioning to a greater degree in more conservative regions.

To test these hypotheses we move to the regional level, using a panel dataset that consists of monthly observations for each of Florida's 24 Workforce Board regions. This dataset spans the period of October 2001 through March 2004 and therefore consists of 30 monthly observations for each region. ${ }^{5}$ Our measure of regional performance is based on the average (monthly) regional ranking (1-24) across the three key measures used by state Workforce Board to monitor regional performance in the WT program - the entered employment rate, the welfare return rate, and the entered wage rate. ${ }^{6}$ We sum the rankings of these measures so that higher scores indicate stronger pressures (i.e., declining performance).

The primary dependent variable for our analyses is the regional sanction rate, which we define as the percentage of each region's monthly caseload that received a sanction in that month. The control variables for our analyses include a variety of characteristics of the adult caseload, including racial/ethnic composition, average age, the work participation rate, family structure, family size, TANF dependency, and the overall size of the monthly adult caseload. (Definitions and descriptive statistics for these variables are presented in the Appendix.) Finally, for each of our analyses we include a full set of

\footnotetext{
${ }^{5}$ This time period reflects the maximum amount of time for which we are able to obtain data for regional performance rankings, regional sanction rates, and the characteristics of TANF clients.

${ }^{6}$ We use the regional ranking, rather than the actual performance measures themselves, because performance incentives are largely based on the region's performance relative to other regions in the state. We measure average regional ranking cumulatively within each fiscal year (i.e., the region's average performance ranking from the first month of the fiscal year (July) through the most recent month) because performance incentives are based on a region's performance across the entire fiscal year. Specifically, we measure regional performance as the monthly change in the average ranking. This reflects our belief that local TANF administrators are likely to be most responsive to the short-term trajectory of the region's performance ranking, rather than the overall ranking itself. Finally, our measure of performance feedback is lagged 2-3 months to account for the lapse of time between the end of the month, the publication of the monthly performance reports by the state (which are not available until the following month), and the communication of the regional response by regional managers to frontline personnel.
} 
regional and monthly fixed effects. The inclusion of regional fixed effects controls for all time-invariant factors that vary across regions, thus providing further control for important differences in regional contexts that may affect client outcomes. The monthly fixed effects control for time-varying variables that do not differ across regions, such as changes in state-level policies that affect all regions.

We begin with a test of the Feedback Hypothesis. The results, presented in the first column of Table 2, are consistent with our expectations: for each one-unit increase in our ranking-based measure of performance pressure, the regional sanction rate increases by an average of about $.13 .^{7}$

\section{[Table 2]}

The Clientele Hypothesis suggests that negative performance feedback should increase sanction rates to a greater degree for hard-to-serve clients who pose more challenges for administrators seeking to meet TANF work goals. Because barriers to labor market success are likely to be greater for black clients than for white clients (Holzer and Stoll 2002), this hypothesis suggests that negative performance feedback should increase sanction rates for black clients more than white clients. ${ }^{8}$ Similarly, we should expect negative performance feedback to increase sanctions for clients with less than 12 years of education to a greater degree than for clients with 12 or more years of education. ${ }^{9}$ The results of these analyses, presented in columns 2-5 of Table 2, generally support our expectations. Performance feedback has a statistically significant effect in all client categories, but the effects are significantly larger among black clients and less-educated clients. The effect among the less educated exceeds the effect among the more educated by approximately 35\%. The effect for black clients is 50\% larger than for white clients.

The Ideology Hypothesis suggests that service-providers in conservative workforce regions, that tend to embrace a stricter welfare-to-work approach, are more likely to turn to sanctions as a response to poor performance feedback. Local environments may affect organizational operations through

\footnotetext{
${ }^{7}$ Because we include a lagged dependent variable in our models, this estimate represents only the immediate effect of performance feedback, with the effect distributed over time through the lagged dependent variable. Even so, this effect is statistically discernible but modest. After six months, the cumulative effect stands at .17.

${ }^{8}$ Although Florida has a large Hispanic population, the uneven dispersion of the Hispanic caseload across the state limits the number of regions for which we can perform an equivalent panel analysis of sanction rates. For this reason, we compare the effects of performance measurement across black and white clients only.

${ }^{9}$ Limited data on client education levels force us to restrict the time period for this analysis to 23 months.
} 
democratic pressures, because officials respond to local conditions and needs, or because officials share the political values of the community (Martin 1992; Feldman 1989; Herzfeld 1992; Cho et al. 2005; Goggin et al. 1990; Weissert 2000). To measure local political variation, we use an index of regional conservatism that we have described elsewhere. ${ }^{10}$ The results, presented in columns 6-7 of Table 2, indicate that performance feedback has no discernable effect on sanction rates in the 12 most liberal workforce regions. In the 12 most conservative regions, the effect is significant and roughly 10 times what we observe in the most liberal regions. In conservative regions, a one-unit increase in our rankingbased measure of performance pressure leads to an immediate increase in the sanction rate of approximately .18. After six months, the cumulative effect is modestly larger, estimated to be 24 .

Extending the logic of our separate hypotheses, we might also expect an interactive effect in which more conservative regions disproportionately sanction hard-to-serve clients in response to negative performance feedback. The results presented in Table 3 are largely consistent with this expectation. In liberal regions, we find no statistically discernible differences across client subgroups in the relationship between negative performance feedback and local sanction rates. In conservative regions, however, we find that clients are sanctioned more frequently in the wake of negative performance feedback in a pattern that disproportionately targets harder-to-serve clients. Sanction rates rise to a significantly greater degree for black clients and clients with low education levels. These results suggest that the Clientele Hypothesis is more accurate for conservative workforce regions than for liberal ones.

[Table 3]

Finally, building on our earlier discussion of "Region A," we should also consider that regional officials might respond to negative performance feedback by pursuing restrictive measures other than sanctions. The case closure rate provides a way to examine the sum total of efforts to remove cases in the face of performance pressure. It is based on regional caseload reports published by the state of Florida and is calculated as the percentage of open cases each month that are closed for reasons other than

\footnotetext{
${ }^{10}$ For details on the construction and validation of this measure, see Fording, Soss, and Schram 2007.
} 
sanctions or earnings. ${ }^{11}$ Although case closures may occur for a variety of reasons, we expect that if local TANF offices are indeed responding to declining performance in a more punitive fashion, this response should be manifested, not only in the rate at which clients are directly pushed off the rolls (i.e., through sanctions), but also in an increase in the rate at which clients leave for other administrative reasons. The results for our analysis are presented in Table 4. As with our model of regional sanction rates, we find that the effect of performance feedback is statistically significant for the full sample of workforce regions (column 1). The slope coefficient suggests that for each increase of one unit our measure of performance pressure, a region's case closure rate is expected to increase by .7 percent. Due to data limitations, we are unable to test the Clientele Hypothesis with case closure data. ${ }^{12}$ Turning to the Ideology Hypothesis, however, we find a pattern similar to the one reported for sanction rates. Performance feedback has no discernible effect on case closures in the twelve most liberal regions, but in the twelve most conservative regions the effect is four times as large and statistically significant. For each unit increase in our performance measure, the case closure rate increases by .012 in these regions. While these effects are smaller than what we find for the sanction rate, the consistency of findings across two dependent variables should bolster our confidence in these results.

[Table 4 here]

Our quantitative results consistently match what we would expect to find if performance pressures motivate service providers to sanction more frequently. Under the strong performance system implemented in 2000, chronic performance pressures have raised sanction rates across the state. Sanction rates under this system are slightly but significantly higher among the for-profit providers we would expect to be especially attuned to the profit implications of performance-based pay points. Episodic declines in performance rankings also appear to heighten performance pressures in ways that lead to increases in sanctioning. Moreover, these effects vary across client subgroups and regions in the ways we

\footnotetext{
${ }^{11}$ We rely on the natural log of the case closure rate for our dependent variable in the analysis that follows.

${ }^{12}$ This is due to the fact that for non-sanction exits, our individual level data do not allow us to distinguish between clients who leave TANF due to earnings and clients who exit for other reasons. However, such data are available to us at the regional level.
} 
would expect if performance pressures have a real impact on sanctioning. While these effects are often modest, their consistency and patterning give us greater confidence in this conclusion.

\section{From Performance Pressures to Sanctioning: A Field Perspective on Mechanisms}

Based on this evidence that performance pressures promote sanctioning in the WT program, we return now to our field research to seek explanations for this relationship. The most obvious candidate for a causal mechanism is suggested by the concept of "creaming” discussed earlier (Bell and Orr 2002). In response to performance pressures, frontline workers use sanctions as an intentional strategy to rid themselves of low-performing clients and, thereby, restrict their caseloads to the "cream" clients who generate positive numbers. This story is intuitively satisfying for a number of reasons. It comports with the "perversely rational" behaviors described in our earlier section on organizational responses. It is consistent with the existing literature on perversity and performance indicators. And it is rooted in logical links that move from system incentives to self-interests to intentions to actions. Sanctions, in this view, are a purposive response to clear systemic incentives.

In this section, we will argue that, despite its consistency with our earlier analysis of organizational responses, this account misrepresents the causal mechanism that links performance pressures to case managers' sanction decisions. Case managers are not single-minded performance maximizers and, moreover, do not believe that higher sanction rates lead to better performance numbers. To specify the links more accurately, we suggest that researchers must adopt an organizational perspective that addresses case managers as situated actors. In the process, our account suggests that a narrow focus on classically rational responses to incentives is likely to obscure a variety of important ways that performance systems can generate perverse outcomes at the frontlines of service provision.

When we started our research, we expected to find a creaming dynamic in case managers' sanction decisions. So why do we now refer to this account as the "causal story that failed"? To begin with, our interviews made it clear that very few case managers are single-minded performance maximizers. They are typically ambivalent actors who try to navigate the cross-pressures of competing values and organizational forces. Most case managers express a strong commitment to social-service 
values that prioritize responsiveness to clients' needs and, as a result, express deep ambivalence about handling client issues with one eye trained on performance goals. Consider the following quotations.

[The WT program] is more business-minded than I would like it to be. [...] To me, this is a social service program, where people aren't just needing to meet goals and achieve the goals on their Individual Responsibility Plan. It's more about what they're going through and the frustrations of it. [...] But then again, [supervisors] would like for us to be business-minded. [...] I would never want to be in a service program if it became all about numbers. [...] Business-minded [means] appointment only. It has be a very professional atmosphere, not a lot of kids running around in the center... whereas our program - hello! - if [clients are] having childcare issues, they're going to have to bring their kids in.

[Welfare in Florida] is no longer a social service; it is a business... I find it to be the difference between herding cattle and herding sheep. A cattle herder is just running people through, not taking time to look after them. A shepherd takes care of the sheep, tends after them, cares for them. It is not my nature to herd cattle and now I have to learn to do that.

It's all about the numbers now, unfortunately. We have to meet our numbers because it affects our funding. I wish we weren't so obsessed with the numbers. Sometimes I feel it [performance pressure] makes me call people just to say "I need that number" [so we can get credit for it] rather than talking about helping them. But I guess it is the nature of the beast. We need to be concerned about the numbers so we can get our funding.

The way we're able to [stay in business and] help people is by making our measurements on our red and green reports and getting paid, so that we can therefore in return help with childcare and support services $[\ldots]$ So the more we make those measurements and those goals, the more we can help candidates. But the more we focus on those [performance goals], the less we're focusing on the candidates. So, it's a catch-22.

They say that we're not, um, how would you say it... a social service agency in a sense, like we're business... But at the same time... you're working with people who have needs, who have barriers, and bringing the two together is very difficult. [...] There's a number game that we have to play. And when you bring that into it, it's hard for me to sit with an individual there; they're telling me that they have all these barriers. For example, they're coming in and they're telling me that they've been evicted from their apartment, they don't have any place to live, they don't have any food, they don't have any clothes. And then here I am as a case manager, you have to participate at 40 hours a week. You know, it’s just kind of, its crazy!”

Ambivalence regarding performance management is matched, on the other side, by ambivalence about sanctions themselves. Like performance indicators, sanctions are central to the ways that case managers in the WT program perceive and pursue their mission. As one official put it, "sanctions are the most important process we have in terms of case management and in terms of producing results." Senior officials and case managers are also virtually unanimous in supporting sanctions, in principle, because they believe frontline workers should impose consequences for client noncompliance. As one case 
manager put it, "I think realistically, you have to have teeth in the program to get people to participate." Yet at the same time, many have doubts about sanctions, in practice, because they worry that clients are set up to fail: they are required to meet a high bar of participation requirements without the supports and services that many need to do so. Thus, many say that sanctions are "educational tools" that are "not punitive at all," yet this view lies uneasily beside the belief that "Florida has a punitive system that gets increasingly harsh the more problems a [client] has. [A sanction] is not a deterrent at all. It's used like a punishment.” Echoing the ambivalence of many, one official confidently asserted that sanctions offer the best way to "stop [clients] from wasting their own time” but later hedged, “To be honest, I'm not always sure what sanctions are good for. Sanctions are just a reality of the program. They don't really deter or gain more attention. They're just how the program works.”

Alongside this ambivalence, however, we found strong and nearly universal adherence to one basic belief: in the WT program, high sanction rates are bad for performance. The creaming account fails to explain sanctioning in the WT program partly because case managers are not single-minded performance maximizers. It fails more fundamentally, however, because virtually no one in the Florida WT program believes that sanctions have a positive effect on performance rankings. Regional officials consistently state that high sanction rates hurt performance and invite unwanted attention from the state. As one put it, “Our region doesn’t want to have a sanction rate that's too high. High numbers (of any kind) draw attention to the region, so it had better be something positive. So we wouldn't want to be seen as overly punitive in a way that might not be within the rules." Case managers consistently told us that "sanctions are helpful for getting the few out that need to be out, but if sanctions get high they hinder [our performance numbers]." Many were quick to add that "[supervisors] want to you to maintain your sanctions as low as possible.” Significantly, this message from supervisors is couched, not just in terms of performance, but also in terms of the values and end goals of the business model. As one case manager explained, “This is a private company, and our goal is to get them employed, not sanctioned.”13

\footnotetext{
13 Confidence that sanctions hurt performance should not be confused with clarity about how, precisely, the two relate. At numerous meetings, we observed regional staff disagreeing about how sanctions factor into performance
} 
Thus, our field research is hard to square with the "creaming" image of case managers as singleminded rational actors who use sanctions intentionally to raise their numbers. Instead our findings point to a more subtle organizational account of how performance pressures influence sanctioning practices. The most plausible mechanisms can be traced, we believe, to the conjunction of four factors: (1) the distinctive ways that the WT program organizes case management; (2) the specific performance pressures experienced by case managers; (3) the limited number of tools available to WT case managers; and (4) case managers’ beliefs and frustrations regarding client non-compliance.

The link between performance pressures and sanctioning is ultimately rooted in the organization of casework. WT case management is highly routinized and focused on tasks related to performance. Caseworkers typically describe themselves as responding to system needs rather than adopting a proactive stance. The following exchange among senior officials offers insight into the nature of the work.

Regional Official A: You don’t hire a “people person” anymore for a career manager position. You hire a clerical computer person. You can teach them the social work stuff easily. The job's all about time, accuracy, and files now. There's a person [client] down there somewhere. But the technical stuff is what matters.

State Official: What you're telling me is the [information] systems are driving the [case management] process.

Several Regional Officials: Oh yes. Oh yes!

Regional Official B: You don’t get any credit [in the performance measures] for hand-holding. You don't get any credit for mentoring. [...]

Regional Official C: If you talk to any case manager here, they will tell you they're not a case manager; they're a technician. They spend about 10 percent of their time on their clients. Their time is about being a technician, and that's the way the program is written. They're doing what they have to do under this system.

WT case management is reactive and clerical. It focuses primarily on documenting client activity hours and entering the results into the One Stop Service Tracking (OSST) data system. Indeed, managers at several levels argued that the data-entry fields of OSST function, in daily organizational routines, as the real policy on the ground. As one put it, “The policy [on the books] doesn't always match up with the specific performance measures, case managers frequently laughed and said that they honestly weren't quite sure. 
[OSST] system. People on the frontlines see the computer screens as the policy. Whatever can or can't be done in a straightforward way on the system, it's assumed that that's the policy.”

When asked to describe their workday, case managers consistently report that they begin by logging on to the information system so they can address the slew of new alerts that arrives each morning. The alerts focus on two kinds of actions: documenting work participation hours for clients and pursuing disciplinary actions when such documentation is lacking. From this point forward, the daily round consists mostly of efforts to do one or the other, punctuated by face-to-face meetings with clients that often focus on the same two issues. Case managers spend most of the day either seeking documentation for work-related activities (a key performance indicator) or taking next steps in the sanction process such as sending out a "pre-penalty” warning letter, requesting a sanction, or working to bring a sanctioned client back into compliance. In short, performance and sanctioning are two sides of a single coin in the work life of the case manager and, together, they stand at the center of the job.

As a result, case managers worry about performance almost continually. As one put it, "It’s just weird, I mean it really is. And I don't know how to explain how, um, you know, we [case managers] all run around and we're like, 'where are you at now with your [participation numbers]?' 'Oh, I'm at like 20 percent.' 'Oh man!' So we're all just stressed!” The stress felt by case managers can be traced partly to their belief that performance numbers matter for job security and trajectory. WT case managers make modest wages in a job with few guarantees, and a non-trivial number have previously received welfare themselves. They often struggle to make ends meet and, as a result, tend to view performance through the prism of their own anxieties as breadwinners. It is not that they expect to be "fired" if their numbers drop; very few hold this view. In a system of for-profit contracting, however, most frontline workers are keenly aware that performance numbers drive profits, and declining profits could lead their current employer to downsize the staff or even to sell the operation to another company whose retention of old employees is uncertain. At a less absolute level, most expect that if they produce weak numbers, they will be subjected to greater supervision in a way that will make their work more stressful and harder to do. One case manager explained, "We [case managers] get our own sanctions. [Laughs] So, um, you know, that's a big 
stress. Um, and they also tell us, 'yeah, the entered employment; um, how many jobs are you getting?' [...] I mean, that’s just things that are hit every day, fifty percent [participation], fifty percent.”

In describing how they handle these pressures, case managers make it clear that they do not see sanctioning as a desirable response. In addition to expecting negative effects on performance numbers, most caseworkers do not like to impose sanctions, and many are skeptical that sanctions have positive effects on clients. One went so far as to assert that "no career manager wants to sanction. You go through all these papers to try to get in touch with the person. It's a struggle. You try to help them get everything in to keep them out of a sanction, but a lot of times you can’t.”

Despite this resistance, our field research makes it clear that sanctions are central to the ways that case managers respond to performance pressures. The primary reason for this dynamic is that case managers have few alternative tools at their disposal. They are limited in what they can do to raise their numbers, and they are even more limited in their abilities to address the real-life problems of their clients. Most caseworkers have no training as social workers; they have few options for matching clients to the services they need; and they are essentially powerless to change clients' opportunities and life conditions. For case managers who feel they have few effective tools at their disposal, the collision of performance pressures and client needs is a deeply frustrating experience. The following quotations illustrate:

Never mind that Deborah can't read, and she's got a $6^{\text {th }}$ grade education, but you want [her to] go out and get a job at ten bucks an hour. Or, my candidate, who has a substance abuse problem, you know, he keeps drinking on the job, that's why he can't keep his job, but [he's] got to go out there and get a job, you know [...So] I think we're more frustrated about meeting our participation rate every single month - that [fifty] percent. [...] It's a big frustration because you're like "I want to make my fifty percent. I don't want to be evaluated at the end of the month and told, "Oh, you didn’t make fifty percent." What do you do?

I hate to sanction people. I really do. I'd rather have them get a job and succeed - but not just any old job, something that would keep them off welfare. And you get that through education. That's the way I feel about it. But we can’t use education anymore [for participation hours].

We try the best not to sanction clients, try to help them overcome barriers. [...] But if we follow regulations and procedures - if they [clients] don't do their part - we have to go by what the program says [and impose that sanction]. Again, we fall back to the same thing. We know that if we sanction, [the clients are] still going to count for participation [rates...]. The program regulations need to be looked at immediately [that the] highest level and [they need to] give us the tools to help clients to a better outcome. 
Frustrated and lacking effective ways to deal with client problems, case managers must find ways to reconcile the pull of competing demands. A small number of case managers square this circle by shifting part of the client's burden onto themselves. They put in long hours to establish whatever documented activities are needed to satisfy performance goals and avoid a sanction. With little time to spare at the office, they often spend hours at the end of a long workday trying to locate clients and secure documentation. As one explained, "My level of sanction is so low. If I were to go by policy [alone], all of [my] caseload would be sanctioned. [...] I go way and beyond [the policy]: a lot of communication, a lot of calling, trying to find where they're at. 'Hey, this is what's going on. If you don't come in, your benefits are going to be stopped.” Case managers in this group meet their performance goals while shielding clients from program requirements and sanctions. Here again, we see how the disciplinary power of performance management occasions its own resistance (Foucault 1980). But it is a subversion that comes at a substantial personal cost. Most case managers in this group report that they are exhausted, burned out, and disappointed that their job is so often about protecting clients from the program itself.

For most WT case managers, performance pressures are a more controlling organizational reality, shaping their use of discretion. Ultimately, most believe that it is the client alone who is responsible for documenting work activities, and it is the client who must, in some way, be motivated to do so. The problem is that, aside from the threat of sanctions, case managers possess few tools for motivating clients. Incentives for good behavior, such as childcare vouchers or transportation assistance, may appear to offer an alternative. In practice, however, appeals to these incentives tend to amount to little more than an implicit threat of sanction. Most benefits for program participants are already available to the client. So the discussion is, at root, about the possibility of a current benefit - or a future transitional benefit - being terminated through a sanction. Thus, as one official explained, sanctions are usually the most effective “tool for helping clients see the benefits of sticking with the program in order to get transitional benefits.”

Although most case managers do not want to impose an actual sanction, they quickly find themselves turning to the threat of a sanction as a way to cajole clients into participating at higher rates and turning in their documentation. When such threats fail, as they often do, case managers find 
themselves initiating "pre-penalty" actions as a way to signal that they "mean business" and that a sanction will be imposed if the client does not do what is required. At this point, organized sanction procedures are set in motion. The computer alerts and requests for action kick in and the caseworker's discretion over the case diminishes. If the client now fails to comply, the case manager confronts strong pressures to move the sanction process forward in a "timely manner.” As one case manager explained:

If you have a customer who turns in fifteen [hours] instead of the 20, at that point in time you can elect to start the penalty process or you can elect to call them and say "Okay, you know what, you have 20 due. It could have just been an oversight or whatever. Can you bring in the other five today, by 5:00 p.m.?” So you have a little flexibility to work it. But once you start that [pre-] penalty, that 8-10 process, there's no way to work around that. It's going to pretty much take its course. Okay, you place the [pre-]penalty on the customer's case; you give them the pre-penalty call. Try and find out, okay, why have you failed to participate? Um, they have the 10 days to comply. [If there's] failure to comply, it will lead to a sanction.

This, then, is the first mechanism that explains how performance pressures increase sanction rates. It is a story of intentional tactics producing unintended and unwanted outcomes. With few tools at their disposal, caseworkers turn to sanction threats in the hope that compliance will ensue, performance numbers will improve, and a sanction will be averted. Once set on this path, however, managers must (however reluctantly) put one foot in front of the other. In a short span of time, they find themselves imposing the sanction that, in the abstract, they see as a hindrance to high performance.

There is also a second mechanism at work, and it is a dynamic that one might expect few case managers to reveal. In a surprising number of instances, case managers report that they sanction clients out of frustration. Performance pressures contribute to this dynamic in two ways. First, as noted above, performance pressures combine with limited tools to produce high levels of frustration at the frontlines. Second, the performance system is structured so that evaluations of the case manager depend on client behavior. When clients fail to turn in documents on time, for example, their actions lower the case manager's performance numbers and invite unwanted scrutiny from supervisors. Not surprisingly, clients tend to become the focal point for case managers' frustrations in such instances. (And it is worth recalling here the extent to which case managers believe that their jobs depend on performance numbers.) 
Under the logic of performance management, the non-compliant client is not just behaving in a way that concerns the case manager; she is behaving in a way that does something to the case manager. As one explained, “The stress is, okay, well I'm caring about this, but the customer doesn't care. So then after a while, you still do what you got to do because you need your job, and you got to make your hours.” A second case manager elaborated:

When it comes to, you know, the problem cases, we get frustrated. I think some people say, "Yeah, technically I could give her another day [to get her documents in], but you know what, I'm gonna slam it [a sanction] on her.” You know? [Laughs...] It's that whole accountability thing. Because we have to be accountable, so I think when you get a customer that doesn't feel that they have to be as accountable, you can get frustrated.

This frustration-sanction dynamic was prevalent enough to be openly discussed at statewide training sessions. In explaining the role of sanctions, one trainer began by observing that "some people want to penalize because they're angry with a client. That's not the point.” In a private interview afterward, a state-level official elaborated: “There [is] no training about case management or emotional issues. Anger management is a big issue. Case managers snap and then sanction because they're mad.”

In sum, then, the causal processes that link performance pressures to sanctioning do not run through the strategic rationality of individual case managers seeking to maximize their numbers. They are more deeply embedded in the organization of case management itself. As performance pressures rain down on the frontlines, case managers are positioned as their ultimate repository yet are given few effective tools for responding. Lacking alternatives, case managers turn to the most basic threat they can wield - the sanction - as a way to motivate client compliance. Predictably, the threat leads to a first procedural step, and what was at first intended as saber-rattling turns into a sanction. At the same time, many case managers become frustrated with clients and perceive an injustice in the fact they are being held accountable while the client is not. In such circumstances, it is not hard to see why case managers often "snap” and levee a sanction that, under other circumstances, they would prefer not to impose.

\section{Conclusion}

In poverty governance today, neoliberal reforms are shrouded by free-market images of autonomy, innovation, and performance enhancement. They are rarely seen or investigated as disciplinary 
regimes. Yet neoliberal performance systems discipline the behaviors of frontline officials just as surely as paternalist sanctions discipline clients. Indeed, the two modes of discipline have strong parallels. Both rest on the threat of penalties for noncompliance; both aim to reshape the motivations of targets so that they will pursue preferred ends as self-regulating subjects, and neither controls behavior completely enough to forestall subversion. Just as welfare clients resist and evade the supervisory regimes of welfareto-work programs (Gilliom 2001), so too do service providers subvert the goals of performance management at the frontlines of welfare reform. As Foucault (1980) notes, this ubiquity of resistance should not be confused with a weakness of disciplinary power. To the contrary, performance pressures have profound effects on consciousness and behavior at the frontlines of welfare reform, and these effects matter greatly for the disciplinary penalties that are meted out to the poor.

In this sense, our analysis of discipline has important implications for how scholars understand street-level discretion. Images of uncontrolled case managers acting on personal whim have been a staple of anxieties regarding welfare reform, even from its inception. Critics on the right have worried that liberal or lazy frontline workers might not really implement the demanding new procedures of welfare-towork programs. Critics on the left have worried that expanded program requirements and tough punitive tools would give case managers carte blanche to treat clients in arbitrary, harmful, and unjust ways. Field studies of welfare provision have often reinforced these anxieties because they make it clear that frontline discretion is endemic; it cannot be eradicated by supervision or procedure; and it functions to rewrite policy on the ground as street-level bureaucrats select, interpret, and adapt the broad rules they inherit.

Our findings do not contradict this conventional wisdom or the studies that have advocated it (e.g., Lipsky 1980; Brodkin 1997; Maynard-Moody and Musheno 2003). Rather, they underscore the perils of reading such studies in a one-sided way that exaggerates individual-worker autonomy by downplaying the organizational forces that shape and channel behavior at the frontlines. The fact that frontline workers are weakly constrained by rules does not mean that they are free to act as they wish. Their uses of discretion are not "ad hoc, unsystematic, or incomprehensible” (Feldman 1992: 163), nor are they mere reflections of individual preference and decision making. Organizational routines, tools, 
norms, incentives, information systems, and categories of understanding function as mechanisms of social control that shape the use of discretion in predictable ways (Baumgartner 1992: 129; Mashaw 1983: 213).

Our analysis of performance management underscores the limits of discretion in the work lives of local program managers and caseworkers. Frontline workers in the Florida WT program do possess considerable discretion in their handling of cases. Their discretion is broad, in the sense that they are authorized to make a wide variety of decisions affecting the client, and it is ineradicable, in the sense that case managers almost always know some way to push a decision in a preferred direction. But case manager discretion does not run very deep if by “deep” one means an individual liberty to treat clients as one would like. Case managers in the WT program are under tremendous performance pressure and have strong incentives to attend to this pressure. The computer key strokes needed to initiate any action, by design, ensure that the case manager's use of discretion will be tracked and monitored through the information system. And partly as a result, case managers make their choices as actors who know they are being observed and evaluated. Interviews with WT case managers suggest that welfare reform has initiated a tougher regime of social control, not just for welfare clients, but also for the employees who serve as their caseworkers. Indeed, our analysis suggests that high rates of sanctioning in the WT program are more closely tied to this organizational regime than to any expectations case managers have about how sanctions actually affect clients or performance numbers. Strong performance pressures promote the use of sanctions to discipline the poor because they are a form of coercive power that drives and directs action and because they are a form of constitutive power that shapes subjective understandings, perceptions, and choices at the frontlines.

To be sure, our analysis also points to a substantial amount of discretion in street-level organizations. We see it, for example, in the case managers who shift burdens onto themselves in an effort to protect clients and in the case managers who act on their personal frustrations by sanctioning in cases where they otherwise would not. We see substantial discretion as well in the ways that program managers pursue strategic but perverse organizational maneuvers in response to performance pressures. Yet a closer look at these examples only serves to underscore the dependence of individual behavior on organizational 
forces. The frustrations that lead some case managers to sanction do not originate in the individual's personal life; they are driven by the organization of WT casework, the pressures of competitive performance systems, and the disciplinary frame of reference in which workers are embedded. Case managers who "burden shift" to protect their clients do, in fact, swim more directly against the organizational tide, but their small numbers and their stories testify to the difficulty of doing so, the substantial personal costs involved, and the forces arrayed against maintaining such a strategy over the long haul. The perverse organizational responses described in the first section of our paper are facilitated by managerial discretion, to be sure. But as our analysis makes clear, these responses are, for the most part, predictable outcomes driven by the structures and processes in which program managers operate.

In this regard, our analysis also raises troubling questions about the new public management and the sharp turn toward performance systems in recent years. We are hardly the first to point out that performance indicators can give rise to perverse organizational responses. But our analysis suggests that such problems may come in a broader variety of forms than previous studies have suggested. Equally important, we find that these problems flow from self-defeating contradictions that are deeply embedded in the new public management - tensions among core principles that are supposed to fit together seamlessly and efficiently. Our analysis of case managers also raises new concerns by underscoring that a narrow focus on the strategic rationality of individuals is likely to reveal only a fraction of the perversity engendered by performance pressures. To understand why case managers impose sanctions that they expect to harm their strategic interests, one must look to broader organizational dynamics and consider how performance pressures affect emotions as well as interests.

None of this suggests that performance management is fated to produce bad results, and we agree with those who argue that systems can be designed to mitigate perversities and failures (Moynihan 2008). Our study suggests, however, that the challenges to doing so are more severe than many acknowledge. Perverse organizational responses do not just arise from incidental or ancillary failures in system design; they are predictable responses to contradictions at the heart of the new public management. 
Through devolution and contracts with diverse organizations, reformers hope to foster local variety and creativity. Yet by placing regional boards and contracted providers in powerful systems of performance competition, reformers force them to respond to uniform pressures that promote conformity and undermine local variety. Performance competition is supposed to motivate local operators to improve their programs as they learn from one another. Yet this very same system fosters a deep distrust of the actors and information that local officials are supposed to learn from. Decentralization is designed to give local officials leeway in deciding how best to respond to performance feedback. Yet this discretion is precisely what allows local managers to forego the "harder path" of serious program reform in favor of “easier paths” such as creative counting and classification schemes, efforts to restrict the client pool, and “stream-creaming” strategies that direct organizational energies toward programs with softer pay points. These and other deeply embedded contradictions promote a system that ignores client needs and undermines the creation and diffusion of beneficial practices at the frontlines.

The new public management suggests to many reformers that they can have their cake and eat it too: centralized control of outcomes and local autonomy; generalization of best practices and diverse solutions tailored to local needs; competition between regions and collaboration among regions. It sounds too good to be true, and it is. Reformers would be better served by an open acknowledgement that features of the new public management lie in tension with one another and tend to work at cross-purposes. It is not possible to maximize the benefits of organizational diversity and locally-tailored problem solving while, at the same time, placing actors in a competitive performance system that promotes conformity and pushes them toward easy rather than challenging paths of innovation. If local diversity and organizational creativity are priorities in a given policy context, performance pressures may need to be eased, at least for a time, to facilitate these goals. And if reformers wish to pursue outcome-focused goals through strong performance systems, they should recognize that their pursuit is likely to come at the cost of some valuable forms of diversity and innovation.

Finally, we would be remiss if we failed to comment on what this organizational analysis tells us about sanctioning itself. Several points stand out. First, sanctioning is more than a response to client 
behaviors and characteristics, and more than an individual action taken by a case manager. Sanctioning is an organized practice and, as a direct result, the frequency and incidence of sanctions are shaped by organizational forces. To ignore these factors, as most studies of sanctioning have, is to promote systematic misunderstandings of what sanctions are and how they are allocated.

Second, performance pressures influence sanctioning in a way that is more deeply perverse than what we find in other areas of our study. We have suggested that organizations respond to performance pressures in a variety of ways that are perverse from the standpoint of program goals but rational from the standpoint of performance-related interests and expectations. In the case of sanctioning, we find a kind of double perversity. When regions are informed of declining performance, they rarely respond in ways that are likely to improve the attainment of program goals. This perversity is compounded, however, by the fact that local organizations also do not respond by shifting their sanctioning behavior in a direction that they expect to raise performance numbers. To the contrary, they respond with higher sanction rates - a development that virtually everyone in the WT program believes will hurt performance. Far from being a rationally chosen operational improvement, performance-driven sanctioning emerges here as an unintended byproduct of organizational forces. It occurs because frontline workers are under great stress, have few tools at their disposal, and grow frustrated when client behaviors put their performance at risk.

Third, additional insight into sanctioning is suggested by the patterning of performance effects across regions, providers, and social groups. Moynihan (2008: 189) urges scholars to attend to the diverse ways that organizations use performance indicators and the "multiple ways in which politics interacts with performance management." These dynamics are put squarely on display by our analysis of sanctioning. When performance indicators go south, ideologically conservative regions crack down and impose more sanctions, while the most liberal regions show no change. For-profits respond to the high financial stakes of performance pay points by sanctioning more often than nonprofits. And when regional performance declines, it is the least powerful and most disadvantaged clients (e.g., racial minorities and those with less education) who are likely to bear the heaviest burdens of increased sanctioning. If it is 
true, as we have argued, that sanctions are products of organizations, and not just client behaviors and characteristics, then it is equally true that sanctions are expressions of power, profit, and ideology. 


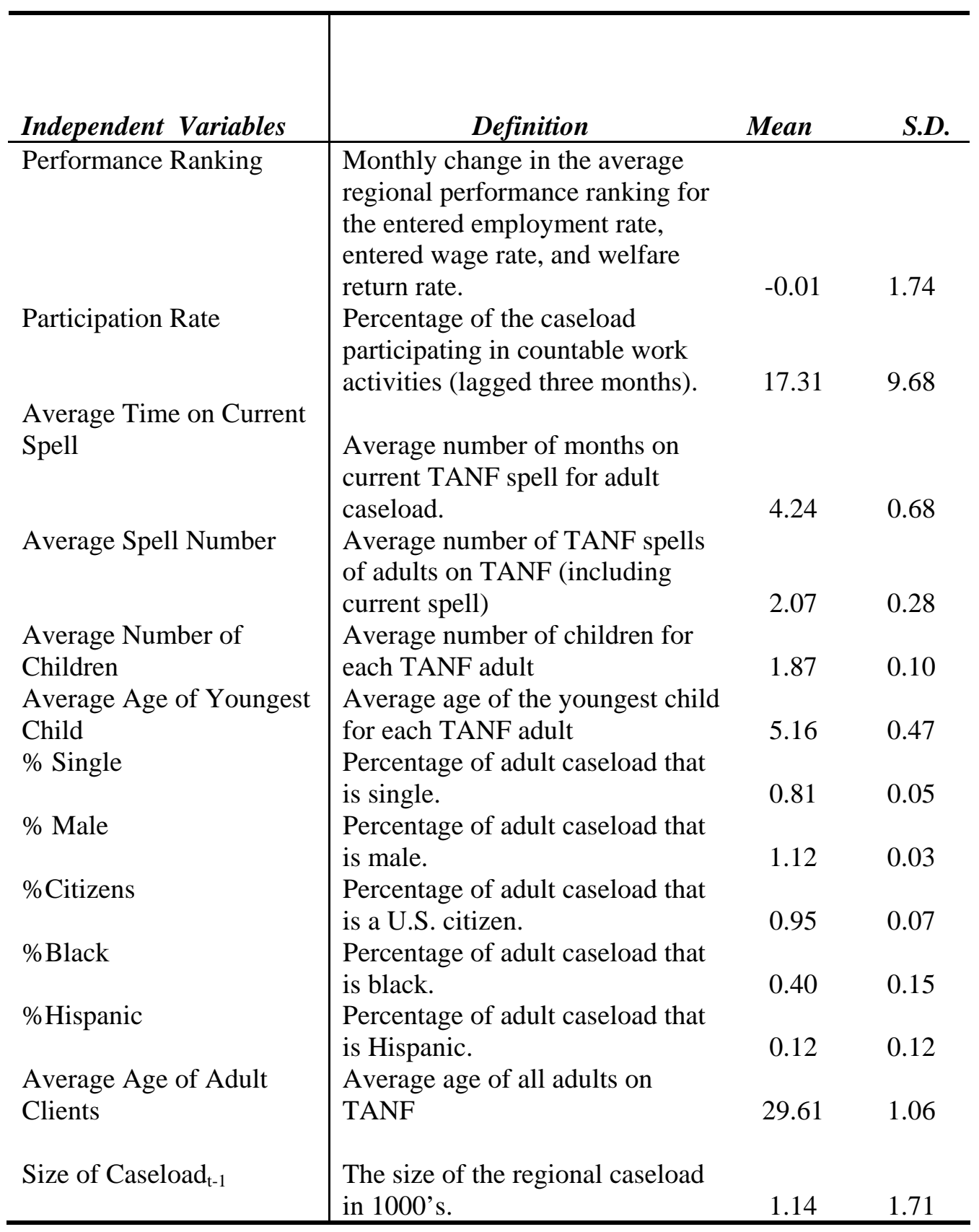

Note: Descriptive statistics are for the full sample of clients. Characteristics of the adult caseload are based on administrative records provided by the Department of Children and Families. Data on regional performance ranking, the participation rate, and the size of the adult caseload were obtained from online reports published by the Agency for Workforce Innovation. 


\section{References}

AWI [Agency for Workforce Innovation]. 2004. Noncompliance and Sanctions Policy. Spring 2004, http://www.floridajobs.org/PDG/TrainingPresentations/WTSanctions051004.pps

Baumgartner, M.P. 1992. “The Myth of Discretion.” In Keith Hawkins, ed. The Uses of Discretion. Oxford: Clarendon Press. Pp.129-62.

Bell, Stephen H. and Larry L. Orr. 2002. "Screening (and Creaming?) Applicants to Job Training Programs: The AFDC Homemaker-Home Health Aide Demonstrations.” Labour Economics 9(2): 279-301.

Botsko, Christopher, Kathleen Snyder, and Jacob Leos-Urbel. 2001. Recent Changes in Florida Welfare and Work, Child Care, and Child Welfare Systems. Washington, DC: Urban Institute.

Brodkin, Evelyn Z. 1997. "Inside the Welfare Contract.” Social Service Review 71(1): 1-33.

Cho, Chung-Lae, Christine A. Kelleher, Deil S. Wright and Susan Webb Yackee. 2005. "Translating National Policy Objectives into Local Achievements across Planes of Governance and among Multiple Actors: Second-Order Devolution and Welfare Reform Implementation.” Journal of Public Administration Research and Theory 15(1):31-54.

Considine, Mark. 2003. "Governance and Competition: The Role of Nonprofit Organizations in the Delivery of Public Services.” Australian Journal of Political Science 38(1): 63-77.

Dias, Janice Johnson and Stephen Maynard-Moody. 2006. "For-Profit Welfare: Contracts, Conflicts, and the Performance Paradox.” Journal of Public Administration Research and Theory 17: 189-211.

Ewalt, Jo Ann, and Edward T. Jennings, Jr. 2004. "Administration, Governance, and Policy Tools in Welfare Implementation.” Public Administration Review 64(4):449-462.

Feldman, Martha. 1989. Order without Design: Information Production and Policy Making. Stanford University Press.

Feldman, Martha S. 1992. “Social Limits to Discretion: An Organizational View.” In Keith Hawkins, ed. The Uses of Discretion. Oxford: Clarendon Press. Pp.163-84.

Foucault, Michel. 1997. [1975] Discipline and Punish: The Birth of the Prison. New York, NY: Vintage.

Foucault, Michel. 1980. “Power and Strategies.” In Colin Gordon, ed. Power/Knowledge - Selected Interviews and Other Writings, 1972-1977. Brighton: Harvester Press. Pp.134-45.

Fording, Richard C., Joe Soss, and Sanford F. Schram. 2007. "Devolution, Discretion and the Impact of Local Political Values on TANF Sanctioning.” Social Service Review 81(2): 285-316.

Gainsborough, Juliet F. 2003. “To Devolve or Not to Devolve? Welfare Reform in the States.” Policy Studies Journal 31(4): 603-23.

Gilliom, John. 2001. Overseers of the Poor: Resistance, Surveillance, and the Limits of Privacy. Chicago, IL: University of Chicago Press.

Goggin, Malcolm, James Lester, Laurence O'Toole, Ann Bowman. 1990. Implementation Theory and Practice: Toward a Third Generation. Scott Foresman.

Hasenfeld, Yeheskel, T.J. Ghose, and Kandyce Hillesland-Larson. 2002. “At Risk of Being Sanctioned: Comparing Sanctioned and Non-Sanctioned Welfare Recipients in California’s CalWORKS.” Paper presented at the Association for Public Policy Analysis and Management's 24th Annual Research Conference, November 7-9, 2002, Dallas, TX.

Hasenfeld, Yeheskel, Toorjo Ghose, Kadyce Larson. 2004. "The Logic of Sanctioning Welfare Recipients: An Empirical Assessment.” Social Service Review 78(2): 304-19.

Heckman, James, Carolyn Heinrich, and Jeffrey Smith (2002). "The Performance of Performance Standards.” Journal of Human Resources, Volume 87, Number 4 (Fall), 778-811.

Heinrich, Carolyn J. 2000. "Organizational Form and Performance: An Empirical Investigation of Nonprofit and For-Profit Job-Training Service Providers.” Journal of Policy Analysis and Management 19(2): 233-261.

Herzfeld, Michael. 1992. The Social Production of Indifference:Exploring the Symbolic Roots of Western Bureaucracy. New York: St. Martin's Press. 
Holzer, Harry J., and Michael A. Stoll. 2002. Employer Demand for Welfare Recipients by Race. Assessing the New Federalism Report 01-07. Washington, DC: Urban Institute. http://www.urban.org/url.cfm?ID 310423

Kalil, Ariel, Kristin S. Seefeldt, and Hui-chen Wang. 2002. "Sanctions and Material Hardship under TANF.” Social Service Review 76(4): 643-62.

Kettl, Donald F. 2005. The Global Public Management Revolution: A Report on the Transformation of Governance. Washington: Brookings Institution.

Lipsky, Michael. 1980. Street-Level Bureaucracy: Dilemmas of the Individual in Public Services. New York: Russell Sage Foundation.

Lurie, Irene. 2006. At the Frontlines of the Welfare System: A Perspective on the Decline in Welfare Caseloads. Albany, NY: State University of New York Press.

Martin, Joanne. 1992. Cultures in Organizations: Three Perspectives. New York: Oxford University Press.

Mashaw, Jerry L. 1983. Bureaucratic Justice. New Haven, CT: Yale Unviersity Press.

Maynard-Moody, Steven and Michael Musheno. 2003. Cops, Teachers, Counselors: Stories from the Front Lines of n Arbor, MI: University of Michigan Press.

Mead, Lawrence M. 2005. Government Matters: Welfare Reform in Wisconsin. Princeton: Princeton University Press.

Mead, Lawrence M. 2000. “Governmental Quality and Welfare Reform.” Paper presented at the 2000 Annual Meeting of the American Political Science Association. Washington, DC: September 1.

Mead, Lawrence M. 1998. “Telling the Poor What to Do.” The Public Interest 132:97-112.

Moynihan, Donald P. 2008. The Dynamics of Performance Management: Constructing Information and Reform. Washington, DC: Georgetown University Press.

Moynihan, Donald P. 2006. "Managing for Results in State Government: Evaluating a Decade of Reform.” Public Administration Review Jan/Feb: 77-89.

Pavetti, LaDonna, Michelle Derr, Gretchen Kirby, Robert Wood, and Melissa Clark. 2004. "The Use of TANF Work-Oriented Sanctions in Illinois, New Jersey and South Carolina.” Washington, DC: Mathematica Policy Research, Inc.

Pavetti, LaDonna, Michelle K. Derr, and Heather Hesketh. 2003. "Review of Sanction Policies and Research Studies: Final Literature Review.” Report prepared for Office of the Assistant Secretary for Planning and Evaluation, Mathematica Policy Research, Washington, D.C.

Radin, Beryl A. 2006. Challenging the Performance Movement: Accountability, Complexity, and Democratic Values. Washington, DC: Georgetown University Press.

Riccucci, Norma. 2005. How Management Matters: Street-level Bureaucrats and Welfare Reform. Washington, DC: Georgetown University Press.

Ridzi, Frank. 2004. "Making TANF Work: Organizational Restructuring, Staff Buy-In, and Performance Monitoring in Local Implementation.” Journal of Sociology and Social Welfare 31, 2 (June):

Sprigings, Nigel. 2002. "Delivering Public Services Under the New Public Management: The Case of Public Housing.” Public Money \& Management 22(4): 11-17.

Talbot, Colin. 2005. “Performance Management.” In E. Ferlie, L.E. Lynn, Jr., and C. Pollitt, eds. The Oxford Handbook of Public Management. Oxford: Oxford University Press. Pp. 491-517.

Weissert, Carol, ed. 2000. Learning from Leaders: Welfare Reform Politics and Policy in Five Midwestern States. Albany: Rockefeller Institute.

Wu, Chi-Fang, Maria Cancian, Daniel R. Meyer, and Geoffrey Wallace. 2006. "How Do Welfare Sanctions Work?” Social Service Review 30(1):33-51. 


\section{Table 1. Effect of Organizational Form on Individual Sanctioning Outcomes}

\begin{tabular}{l|c}
\hline & \\
Independent Variables & Odds Ratio \\
\hline Unmarried & $0.88^{* *}$ \\
Black & 0.98 \\
Hispanic & 0.99 \\
Number of Children & $0.97 *$ \\
Age of Youngest Child & 1.00 \\
Gender (Male=1) & $1.23^{* *}$ \\
Citizen & $1.17^{*}$ \\
Age (years) & $0.98^{* *}$ \\
Spell Length (Months) & $1.08^{* *}$ \\
Local Conservatism & 1.06 \\
Local Unemployment Rate & 1.03 \\
Per Capita Caseload & 0.00 \\
\hline Sample Size & $1.25^{*}$ \\
\hline Fof & -32786.595 \\
\hline
\end{tabular}

Note: The coefficient entries are odds ratios, based on a logit analysis.

Significance tests are based on robust standard errors, adjusted for clustering by workforce board region. 
Table 2. Effects of Regional Performance Measures on Regional Sanction Rates

\begin{tabular}{|c|c|c|c|c|c|c|c|}
\hline \multirow[b]{2}{*}{ Independent Variables } & \multirow[b]{2}{*}{ All Clients } & \multicolumn{2}{|c|}{ Race of Clients } & \multicolumn{2}{|c|}{ Clients' Education } & \multicolumn{2}{|c|}{ Political Ideology } \\
\hline & & Black & White & $<12$ yrs. & $\geq 12$ yrs. & $\begin{array}{c}\text { Most } \\
\text { Liberal }\end{array}$ & $\begin{array}{c}\text { Most } \\
\text { Conservative }\end{array}$ \\
\hline Performance Ranking & $.127 * *$ & $.200 * *$ & $.137 *$ & $.234^{* *}$ & $.173^{* *}$ & .017 & $.180^{* *}$ \\
\hline Participation Rate & $-.074 * *$ & $-.126^{* *}$ & -.033 & $-.101 * *$ & $-.093 * *$ & $-.124 * *$ & -.037 \\
\hline Average Time on Current Spell & $-.873 * *$ & -.357 & $-1.205^{* *}$ & $-1.807 * *$ & -.642 & $-1.967^{* *}$ & -.437 \\
\hline Average Spell Number & -1.877 & -.962 & $-2.707 *$ & -2.227 & -1.798 & -.965 & $-5.552 * *$ \\
\hline Average Number of Children & $3.980 *$ & 1.738 & 2.392 & 3.066 & .909 & .189 & 3.910 \\
\hline Average Age of Youngest Child & -.181 & -.047 & .808 & -.375 & .096 & $-1.746^{* *}$ & 1.274 \\
\hline$\%$ Single & -.069 & -.054 & -.046 & -.053 & .077 & .049 & -.043 \\
\hline$\%$ Male & .061 & -.035 & .119 & -.072 & .098 & .012 & .198 \\
\hline \%Citizens & -.180 & $-.339 *$ & .077 & .024 & -.050 & .142 & $-.464 * *$ \\
\hline \%Black & $-.147 * *$ & --- & --- & -.036 & $-.122^{* *}$ & $-.238 * *$ & -.140 \\
\hline \%Hispanic & $-.166^{*}$ & --- & --- & -.005 & -.125 & .020 & $-.333 * *$ \\
\hline Average Age of Adult Clients & -.316 & $-.878 * *$ & -.191 & -.031 & -.561 & .311 & -.792 \\
\hline Size of Caseload $\mathrm{t}_{\mathrm{t}-1}$ & -.450 & -.661 & $-1.328 *$ & $-2.161^{* *}$ & -.282 & $-1.117^{*}$ & 1.249 \\
\hline Sanction Rate $_{t-1}$ & $.271 * *$ & $.240 * *$ & $.137 * *$ & $.131 * *$ & .084 & $.241^{* *}$ & $.245^{*}$ \\
\hline $\begin{array}{l}\mathrm{R}^{2} \\
\text { Sample Size }\end{array}$ & $\begin{array}{c}.58 \\
(\mathrm{~N}=720)\end{array}$ & $\begin{array}{c}.48 \\
(\mathrm{~N}=720)\end{array}$ & $\begin{array}{c}.46 \\
(\mathrm{~N}=720)\end{array}$ & $\begin{array}{c}.52 \\
(\mathrm{~N}=552)\end{array}$ & $\begin{array}{c}.49 \\
(\mathrm{~N}=552)\end{array}$ & $\begin{array}{c}.68 \\
(\mathrm{~N}=360)\end{array}$ & $\begin{array}{c}.48 \\
(\mathrm{~N}=360)\end{array}$ \\
\hline
\end{tabular}

${ }^{* *} \mathrm{p}<.05,{ }^{*} \mathrm{p}<.10$, two-tailed test

Note: The dependent variable is the monthly sanction rate (\# sanctioned / caseload * 100). Performance Ranking is defined as the change in the average monthly ranking (1-24) for the entered wage rate, the welfare return rate, and the entered employment rate. This variable is measured at a lag of three months and is measured cumulatively within each fiscal year. Slope coefficients are estimated by OLS, while significance tests are based on panel corrected standard errors. All models are estimated with a full set of fixed effects for workforce regions and month of analysis. 
Table 3. Effect of Regional Performance Measures on Regional Sanction Rates, by Local Political Culture and Race of Client

\begin{tabular}{|c|c|c|c|c|c|c|c|c|}
\hline \multirow{2}{*}{$\begin{array}{l}\text { Independent } \\
\text { Variables }\end{array}$} & \multicolumn{2}{|c|}{$\begin{array}{l}\text { Most Liberal } \\
\text { Regions }\end{array}$} & \multicolumn{2}{|c|}{$\begin{array}{l}\text { Most Liberal } \\
\text { Regions }\end{array}$} & \multicolumn{2}{|c|}{$\begin{array}{c}\text { Most Conservative } \\
\text { Regions }\end{array}$} & \multicolumn{2}{|c|}{$\begin{array}{c}\text { Most Conservative } \\
\text { Regions }\end{array}$} \\
\hline & Black & White & $<12$ yrs. & $\geq 12$ yrs. & Black & White & $<12$ yrs. & $\geq 12$ yrs. \\
\hline $\begin{array}{l}\text { Performance } \\
\text { Ranking }\end{array}$ & .055 & .045 & -.030 & .153 & $.290 * *$ & $.176^{*}$ & $.346^{* *}$ & .131 \\
\hline $\begin{array}{l}\text { Participation } \\
\text { Rate }\end{array}$ & $-.117 * *$ & $-.075^{* *}$ & $-.168 * *$ & $-.138 * *$ & $-.120 * *$ & .013 & -.059 & $-.099 * *$ \\
\hline $\begin{array}{l}\text { Avg. Time on } \\
\text { Current Spell }\end{array}$ & $-1.044 * *$ & $-1.690 * *$ & $-1.798 * *$ & -.386 & .608 & -.511 & $-1.687 * *$ & -.353 \\
\hline $\begin{array}{l}\text { Avg. Spell } \\
\text { Number }\end{array}$ & 1.612 & -1.849 & -.401 & -1.095 & -1.512 & $-6.685 * *$ & -3.717 & -3.428 \\
\hline $\begin{array}{l}\text { Avg. Number } \\
\text { of Children }\end{array}$ & 1.346 & 4.118 & .109 & -3.022 & 1.679 & 1.165 & 3.594 & .682 \\
\hline $\begin{array}{l}\text { Avg. Age of } \\
\text { Youngest Child }\end{array}$ & -.597 & .566 & -1.213 & -1.516 & .573 & .584 & .190 & 1.173 \\
\hline \% Single & $-.286 * *$ & .067 & $-.283 * *$ & $.199 *$ & .046 & -.067 & .007 & -.033 \\
\hline \% Male & $-.481^{* *}$ & .132 & $-.450 * *$ & $.371^{* *}$ & .196 & .171 & .057 & -.110 \\
\hline \%Citizens & $-.613^{* *}$ & -.292 & .211 & .186 & -.297 & .341 & .049 & -.128 \\
\hline \%Black & --- & --- & -.132 & $-.214 * *$ & --- & --- & .059 & -.035 \\
\hline \%Hispanic & --- & --- & .245 & .180 & --- & --- & -.041 & -.187 \\
\hline $\begin{array}{l}\text { Avg. Age of } \\
\text { Adult Clients }\end{array}$ & -.659 & -.163 & -.143 & -.027 & $-1.122^{* *}$ & -.222 & .144 & $-1.015^{* *}$ \\
\hline $\begin{array}{l}\text { Size of } \\
\text { Caseload }_{t-1}\end{array}$ & .031 & $-2.102^{* *}$ & -1.256 & -.840 & -1.757 & 1.618 & $-12.858 * *$ & $-6.696 *$ \\
\hline Sanction Rate $_{\mathrm{t}-1}$ & $.202 * *$ & $.168 * *$ & .120 & .012 & $.236 * *$ & .080 & .054 & .081 \\
\hline $\begin{array}{l}\mathrm{R}^{2} \\
\text { Sample Size }\end{array}$ & $\begin{array}{c}.59 \\
(\mathrm{~N}=360)\end{array}$ & $\begin{array}{c}.53 \\
(\mathrm{~N}=360)\end{array}$ & $\begin{array}{c}.65 \\
(N=276)\end{array}$ & $\begin{array}{c}.59 \\
(\mathrm{~N}=276)\end{array}$ & $\begin{array}{c}.42 \\
(N=360)\end{array}$ & $\begin{array}{c}.40 \\
(\mathrm{~N}=360)\end{array}$ & $\begin{array}{c}.42 \\
(\mathrm{~N}=276)\end{array}$ & $\begin{array}{c}.46 \\
(\mathrm{~N}=276)\end{array}$ \\
\hline
\end{tabular}

${ }^{* *} \mathrm{p}<.05,{ }^{*} \mathrm{p}<.10$, two-tailed test

Note: The dependent variable is the monthly sanction rate (\# sanctioned / caseload * 100). Performance Ranking is defined as the change in the average monthly ranking (1-24) for the entered wage rate, the welfare return rate, and the entered employment rate. This variable is measured at a lag of three months and is measured cumulatively within each fiscal year. Slope coefficients are estimated by OLS, while significance tests are based on panel corrected standard errors. All models are estimated with a full set of fixed effects for workforce regions and month of analysis. 


\section{Table 4. Effect of Regional Performance Measures on Regional Case Closure Rates}

\begin{tabular}{|c|c|c|c|}
\hline Independent Variables & All Regions & $\begin{array}{l}\text { Liberal } \\
\text { Regions }\end{array}$ & $\begin{array}{c}\text { Conservative } \\
\text { Regions } \\
\end{array}$ \\
\hline Performance Ranking & $.007 *$ & .003 & $.012^{* *}$ \\
\hline Participation Rate & .001 & $.004 * *$ & $-.003^{*}$ \\
\hline Average Time on Current Spell & .005 & $.093 * *$ & -.012 \\
\hline Average Spell Number & 119 & $.464 * *$ & $.299 *$ \\
\hline Average Number of Children & -.023 & .004 & .092 \\
\hline Average Age of Youngest Child & .056 & -.013 & $.117^{*}$ \\
\hline Average Age of Adult Clients & .027 & .013 & -.000 \\
\hline \% Single & -.001 & -.011 & -.001 \\
\hline$\%$ Male & -.011 & $-.028 * *$ & -.004 \\
\hline \%Citizens & -.008 & -.012 & $-.022 *$ \\
\hline \%Black & -.005 & -.007 & -.001 \\
\hline \%Hispanic & .004 & .006 & -.001 \\
\hline Size of Caseload ${ }_{t-1}$ & .013 & $.084 * *$ & .021 \\
\hline Case Closure Rate $_{t-1}$ & $.099 *$ & $.162 * *$ & -.047 \\
\hline $\begin{array}{l}\mathrm{R}^{2} \\
\text { Sample Size }\end{array}$ & $\begin{array}{c}.51 \\
(\mathrm{~N}=720)\end{array}$ & $\begin{array}{c}.68 \\
(\mathrm{~N}=360)\end{array}$ & $\begin{array}{c}.39 \\
(\mathrm{~N}=360)\end{array}$ \\
\hline
\end{tabular}

Note: The dependent variable is the natural log of the monthly case closure rate (\# cases closed / caseload * 100). Cases closed in this measure are for reasons other than sanction or earnings. Performance Ranking is defined as the change in the average monthly ranking (1-24) for the entered wage rate, the welfare return rate, and the entered employment rate. This variable is measured at a lag of two months and is measured cumulatively within each fiscal year. Slope coefficients are estimated by OLS, while values in parentheses are panel-corrected standard errors. The period of analysis is October 2001 - March 2004 (30 months). All models are estimated with a full set of fixed effects for workforce regions and month of analysis. 
Figure 1. Caseload Effects of Organizational Change in "Region A"

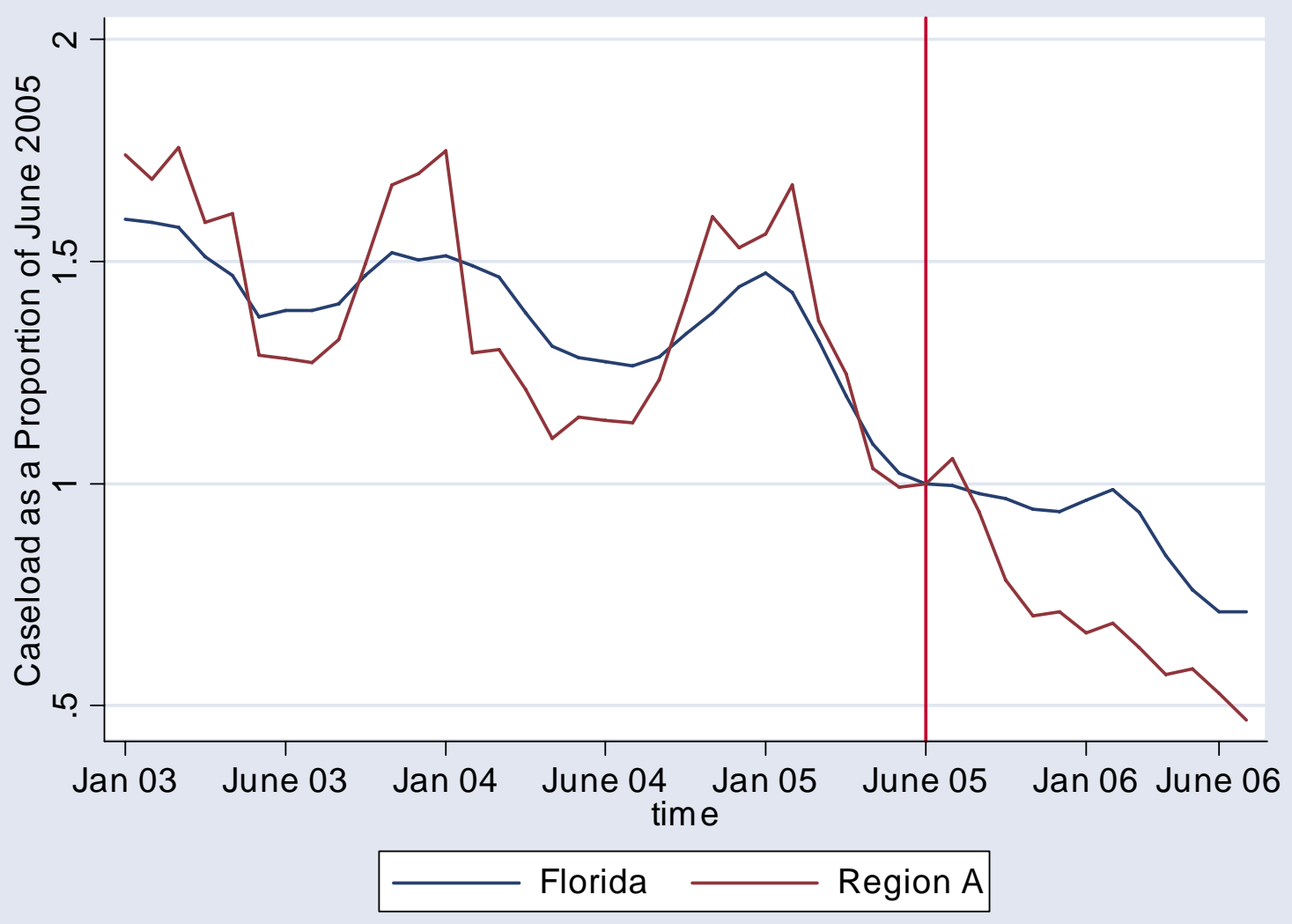

Note: All values are expressed as a proportion of the June 2005 caseload. Entries for "Florida" are based on the 23 workforce regions other than Region A. 
Figure 2. Change in the Welfare Sanction Rate over Time: The Transition to WT

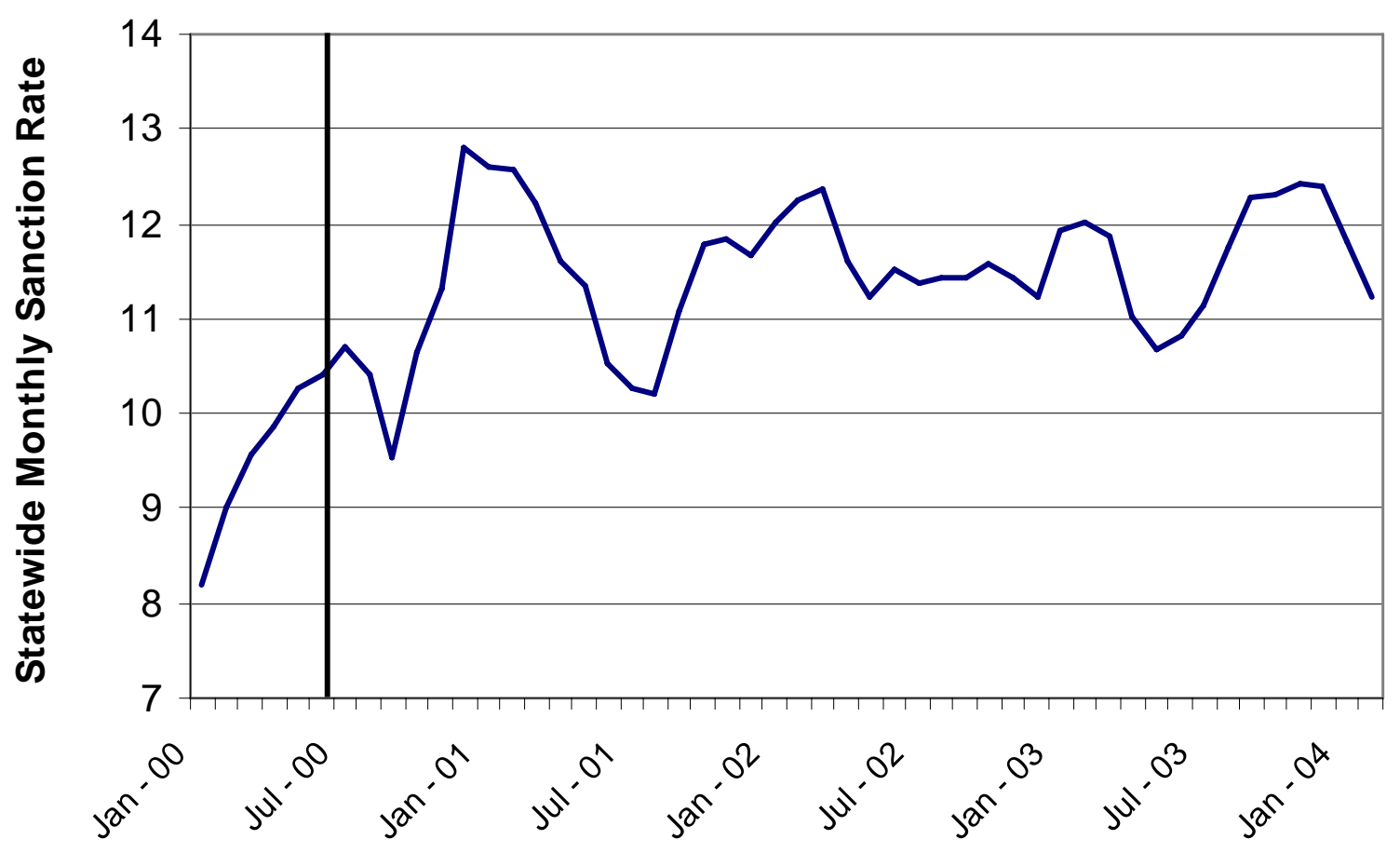

Note: Values represent the average statewide sanction rate at each point in time, measured as the mean of three-month moving averages calculated for each of the 24 workforce regions. 